\title{
Daptomycin exerts rapid bactericidal activity against Bacillus anthracis without disrupting membrane integrity
}

\author{
Yu-hua XING ${ }^{1,2}$, Wei WANG ${ }^{1,2}$, Su-qin DAI ${ }^{1}$, Ti-yan LIU ${ }^{1}$, Jun-jie TAN ${ }^{1}$, Guo-long QU ${ }^{1}$, Yu-xia LI ${ }^{1}$, Yan LING ${ }^{1}$, Gang LIU ${ }^{1, *}$, \\ Xue-qi FU², Hui-peng CHEN $^{1}$ \\ ${ }^{1}$ Beijing Institute of Biotechnology, Beijing 100071, China; ${ }^{2}$ College of Life Science, Jilin University, Changchun 130012, China
}

\begin{abstract}
Aim: To examine whether the novel cyclic lipopeptide antibiotic daptomycin could be used to treat anthrax and to study the mechanisms underlying its bactericidal action against Bacillus anthracis.

Methods: Spore-forming B anthracis AP422 was tested. MIC values of antibiotics were determined. Cell membrane potential was measured using flow cytometric assays with membrane potential-sensitive fluorescent dyes. Cell membrane integrity was detected using To-Pro-3 iodide staining and transmission electron microscopy. $\mathrm{K}^{+}$efflux and $\mathrm{Na}^{+}$influx were measured using the fluorescent probes PBFI and SBFI-AM, respectively.

Results: Daptomycin exhibited rapid bactericidal activity against vegetative $B$ anthracis with a MIC value of $0.78 \mu g / m L$, which was comparable to those of ciprofloxacin and penicillin $\mathrm{G}$. Furthermore, daptomycin prevented the germinated spores from growing into vegetative bacteria. Daptomycin concentration-dependently dissipated the membrane potential of $B$ anthracis and caused $\mathrm{K}^{+}$efflux and $\mathrm{Na}^{+}$influx without disrupting membrane integrity. In contrast, both ciprofloxacin and penicillin $\mathrm{G}$ did not change the membrane potential of vegetative bacteria or spores. Penicillin G disrupted membrane integrity of $B$ anthracis, whereas ciprofloxacin had no such effect.
\end{abstract}

Conclusion: Daptomycin exerts rapid bactericidal action against $B$ anthracis via reducing membrane potential without disrupting membrane integrity. This antibiotic can be used as an alternate therapy for $B$ anthracis infections.

Keywords: anthrax; Bacillus anthracis; antibiotic; daptomycin; ciprofloxacin; penicillin; CCCP; nisin; valinomycin; membrane potential; membrane integrity

Acta Pharmacologica Sinica (2014) 35: 211-218; doi: 10.1038/aps.2013.159; published online 23 Dec 2013

\section{Introduction}

Anthrax is an acute disease caused by Bacillus anthracis (B anthracis), a Gram-positive, spore-forming rod. Anthrax is primarily a disease of animals and could affect humans ${ }^{[1]}$. When spores are inhaled, ingested or come in contact with a skin lesion on a host, they may germinate into vegetative bacteria. Vegetative $B$ anthracis can replicate rapidly and produce toxins that cause the death that is associated with severe anthrax infections. The potential use of anthrax spores as a biological warfare weapon remains a significant concern ${ }^{[2]}$. Effective antibiotic treatments are crucial to prevent the possible death caused by inhalation anthrax because of the current shortage of vaccines and the lack of toxin-neutralizing agents. FDAapproved agents for anthrax treatment include ciprofloxacin,

\footnotetext{
* To whom correspondence should be addressed.

E-mail jueliu@sohu.com

Received 2013-05-12 Accepted 2013-09-28
}

doxycycline and penicillin ${ }^{[3,4]}$. However, its ability to develop resistance to antimicrobial agents is currently a major concern. For example, although penicillin is considered the treatment of choice for all forms of anthrax, many penicillin-resistant strains and treatment failures have been reported in the literature ${ }^{[5-7]}$. Reports of $B$ anthracis resistance to ciprofloxacin and other antibiotics have likewise appeared ${ }^{[8-11]}$. It is, therefore, important to reevaluate the spectrum of antibiotics and to develop new drugs that are available for anthrax treatment.

Daptomycin is a novel cyclic lipopeptide antibiotic that was approved by the FDA in 2003 for the treatment of serious skin and skin-structure infections caused by Gram-positive pathogens. This drug exerts strong bactericidal activities in vitro against most clinically relevant, gram-positive pathogens $^{[12]}$. Its unique mode of action ${ }^{[13]}, i e$, inserting into bacterial membrane and perturbing membrane function, makes it a useful alternate therapeutic for $B$ anthracis infection if resistant isolates emerged. However, limited data are available on the 
effect of this drug on $B$ anthracis species, and only one study has been reported by Heine $e t a l^{[14]}$. This group demonstrated that daptomycin was active against $B$ anthracis using a murine model of spore inhalation. In this model, treatment with daptomycin for $21 \mathrm{~d}$ protected $90 \%$ of the tested mice, which was equivalent to those treated with ciprofloxacin and might be sufficient to achieve a cure.

$B$ anthracis exists as two forms: vegetative bacteria and spores. In this study, we used B anthracis AP422 as a model, which was derived from the Chinese vaccine strain A16R as an attenuated, nontoxinogenic, and nonencapsulated mutant strain capable of sporulation. We wished to assess the in vitro activity of daptomycin against vegetative bacteria and spores and further investigate its novel mode of action against $B$ anthracis compared to other potential anthrax-therapeutic antibiotics.

\section{Materials and methods}

\section{Bacterial strains, growth media, and chemicals}

$B$ anthracis AP422 [pXO1-, pXO2-] CGMCC № 1569, which was derived from the Chinese vaccine strain A16R, is an attenuated, nontoxinogenic and nonencapsulated mutant strain that can sporulate and was kindly provided by Prof Chunjie LIU (Beijing Institute of Biotechnology, China). B anthracis was grown in Mueller-Hinton broth (MHB) (Difco Laboratories, Detroit, $\mathrm{MI}$, USA) with $1.25 \mathrm{mmol} / \mathrm{L}$ of $\mathrm{Ca}^{2+}(\mathrm{MHBc})$ at $37^{\circ} \mathrm{C}$ with agitation at $2.2 \times g$.

Daptomycin was purchased from Cubist Pharmaceuticals, Inc (Lexington, MA, USA). CCCP, Nisin, Penicillin G, Ciprofloxacin and Valinomycin were obtained from Sigma Chemical Company (St Louis, MO, USA). Each antibiotic was prepared as a stock solution, and further working concentrations were prepared in Mueller-Hinton broth. Fluorescent dyes $\mathrm{DiSC}_{3}(5)$, $\mathrm{DiOC}_{2}(3)$, To-Pro-3 iodide, PBFI, SBFI-AM, and Pluronic F-127 were obtained from Invitrogen-Molecular Probes (Eugene, OR, USA).

\section{Antibiotic susceptibility assay}

MICs (minimum inhibitory concentration) were determined by two-fold broth microdilution in 96-well plates according to the current Clinical and Laboratory Standards Institute (CLSI) guidelines $^{[15]}$. The MIC was defined as the lowest drug concentration that prevented visible turbidity after $18 \mathrm{~h}$ of incubation at $37^{\circ} \mathrm{C}$. These susceptibility studies were carried out on three different occasions in duplicate.

\section{Measuring the activity of daptomycin against $B$ anthracis}

$B$ anthracis AP422 vegetative cells and spores were prepared as described previously ${ }^{[16]}$. The vegetative cell and spore preparations had purity $>98 \%$ and were used at concentrations of $4 \times 10^{6} \mathrm{CFU} / \mathrm{mL}$ and $1 \times 10^{6}$ spores/mL, respectively. Daptomycin, ciprofloxacin and penicillin $G$ were added to the suspensions for bactericidal or sporicidal activity assays, and drug-free water was used as a negative control. After being exposed to antibiotics, culture aliquots were removed, serially diluted in MHB and plated in agar for CFU determination.

\section{Determination of membrane potential}

The membrane potential was measured using the membrane potential-sensitive fluorescent dye $\operatorname{DiSC}_{3}(5)^{[17]}$. B anthracis cells and spores were grown in $\mathrm{MHBc}$ to early exponential phase $\left(O D_{600}=0.3\right)$ and treated with daptomycin and comparative antibiotics at concentrations equal to five times the MIC at $37^{\circ} \mathrm{C}$. At appropriate time points, $\operatorname{DiSC}_{3}(5)(2 \mu \mathrm{mol} / \mathrm{L})$ was added and incubated for $15 \mathrm{~min}$ at room temperature. The fluorescence reading was monitored using a Perkin-Elmer Envision Multilabel Reader (Perkin-Elmer Inc, Waltham, MA, USA), the cells were excited at $622 \mathrm{~nm}$, and the fluorescence emission was measured at $670 \mathrm{~nm}$. A blank with only cells and the dye was used to subtract the background.

\section{Determination of membrane integrity}

Flow cytometric methods were performed to determine the membrane potential and membrane integrity ${ }^{[18]}$. B anthracis cultures grown in MHBc $\left(O D_{600}=0.3\right)$ were treated with daptomycin or comparative antibiotics, and the samples were stained with $30 \mu \mathrm{mol} / \mathrm{L} \mathrm{DiOC}_{2}(3)$ and $100 \mathrm{nmol} / \mathrm{L}$ To-Pro-3 iodide for $4 \mathrm{~min}$. Data were analyzed using a BD FACSCalibur Flow Cytometer. $\mathrm{DiOC}_{2}(3)$ was excited at $488 \mathrm{~nm}$, its green fluorescence was detected through a 530 $\pm 20-\mathrm{nm}$ bandwidth band-pass filter, and its red fluorescence was detected through a $610 \pm 19-\mathrm{nm}$ bandwidth band-pass filter. The ratio of red fluorescence to green fluorescence provides a cell sizeindependent measure of the membrane potential. To-Pro-3 iodide was excited by a helium-neon laser, and its far-red fluorescence was detected through a 695-nm, long-pass filter and was indicative of membrane damage. Cells killed by heat exposure $\left(100^{\circ} \mathrm{C}\right.$ for $\left.10 \mathrm{~min}\right)$ were used as positive controls for To-Pro-3 iodide staining.

\section{Transmission electron microscopy}

$B$ anthracis cells were grown in $\mathrm{MHBc}$ to $O D_{600}=0.4$ and treated with daptomycin and comparative antibiotics, as described above. Then, cells were centrifuged at $94 \times g$, for $10 \mathrm{~min}$, washed twice with PBS and preserved in a fixative (3\% glutaraldehyde in $0.1 \mathrm{~mol} / \mathrm{L}$ PBS buffer). Samples were post-fixed in $1 \%$ osmium tetroxide, dehydrated in graded ethanol and infiltrated with acetone. The samples were then embedded in Epon Lx-112 resin ${ }^{[19]}$, and thin sections of the specimens were viewed using a HITACHI H7650 transmission electron microscope.

\section{Potassium ion efflux and sodium influx assays}

$\mathrm{K}^{+}$release assay was performed using the $\mathrm{K}^{+}$-specific fluorescent probe $\mathrm{PBFI}^{[20]}$. $B$ anthracis was grown in $\mathrm{MHBc}$ $\left(O D_{600}=0.3\right)$ and resuspended in $10 \mathrm{mmol} / \mathrm{L}$ HEPES $(\mathrm{pH} 7.2)$ and $0.5 \%$ glucose containing $10 \mu \mathrm{mol} / \mathrm{L} \mathrm{PBFI.} \mathrm{Data} \mathrm{were} \mathrm{ana-}$ lyzed using a Perkin-Elmer EnSpire Multilabel Reader, cells were excited at $346 \mathrm{~nm}$, and the fluorescence emission was measured at $505 \mathrm{~nm}$ to establish a baseline signal before the addition of antibiotics, after which data were collected for 10 min. Valinomycin $(10 \mu \mathrm{g} / \mathrm{mL})$ was used as the positive control. The uptake of $\mathrm{Na}^{+}$into the cytoplasm was measured by 
the acetoxymethyl ester of the fluorescent, sodium-binding reagent benzofuran isopthalate (SBFI-AM) ${ }^{[21]}$. Cells were incubated in Locke's buffer $(154 \mathrm{mmol} / \mathrm{L} \mathrm{NaCl} ; 5.6 \mathrm{mmol} / \mathrm{L} \mathrm{KCl}$; $1.0 \mathrm{mmol} / \mathrm{L} \mathrm{MgCl}_{2} ; 2.3 \mathrm{mmol} / \mathrm{L} \mathrm{CaCl}_{2} ; 5.6 \mathrm{mmol} / \mathrm{L}$ glucose; $8.6 \mathrm{mmol} / \mathrm{L}$ HEPES; and $0.1 \mu \mathrm{mol} / \mathrm{L}$ glycine, $\mathrm{pH} 7.4)$, containing $10 \mu \mathrm{mol} / \mathrm{L}$ SBFI-AM and $0.02 \%$ Pluronic F-127 for $1 \mathrm{~h}$ at $37^{\circ} \mathrm{C}$. The SBFI fluorescence ratios $(340 / 380)$ versus time were then analyzed, and the emission wavelength was $505 \mathrm{~nm}$.

\section{Statistical analysis}

Data are expressed as the mean $\pm S D$, and error bars represent standard deviations (SD). $P$ values were calculated using Student's $t$-test by and a paired, one-tailed distribution with the SAS software version 8.0. $P<0.05$ indicates statistical significance.

\section{Results}

\section{In vitro antimicrobial susceptibility}

A susceptibility test was performed in MHBc according to the guidelines of the current Clinical and Laboratory Standards Institute (CLSI) using the Staphylococcus breakpoints. The MICs of the antibacterial agents that were tested against $B$ anthracis AP422 are shown in Table 1. The MIC of daptomycin for B anthracis AP422 was $0.78 \mu \mathrm{g} / \mathrm{mL}$ below the accepted breakpoints.

Table 1. In vitro activity of daptomycin and other antibacterials against $B$ anthracis AP422.

\begin{tabular}{lc}
\hline Agents & $\mathrm{MIC}(\mu \mathrm{g} / \mathrm{mL})$ \\
\hline Daptomycin & $0.78 \pm 0.09$ \\
Penicillin G & $0.2 \pm 0.03$ \\
Ciprofloxacin & $0.2 \pm 0.02$ \\
Valinomycin & $1.56 \pm 0.2$ \\
Nisin & $6.25 \pm 0.5$ \\
CCCP & $2 \pm 0.3$ \\
\hline
\end{tabular}

\section{Activity of daptomycin against B anthracis AP422}

The results demonstrated that daptomycin had rapid and concentration-dependent bactericidal activity against $B$ anthracis AP422 $(1 \times$ to $8 \times$ the MIC). At $1 \times$ the MIC, daptomycin inhibited AP422 growth for $1 \mathrm{~h}$, but the counts increased by $1 \log 10$ unit after overnight incubation. In contrast, $4 \mu \mathrm{g} / \mathrm{mL}(5 \times$ the MIC) daptomycin reduced the counts by $>3 \log 10$ after $2 \mathrm{~h}$, then a reduction of $4 \log 10$ was observed, and this effect was sustained for $18 \mathrm{~h}$ (Figure 1A). The effects of treatment with daptomycin $(5 \times \mathrm{MIC})$ were equal to those with ciprofloxacin $(5 \times \mathrm{MIC})$ and penicillin $\mathrm{G}(5 \times \mathrm{MIC})$ (Figure 1B).

Interestingly, a delay in the growth of the spores that were incubated in MHBc was evident when compared with vegetative cells, indicating that the spores required time to germinate into vegetative $B$ anthracis cells before they could replicate. When the spores were incubated in MHBc supplemented with daptomycin, a similar lag time initially occurred, but subse-
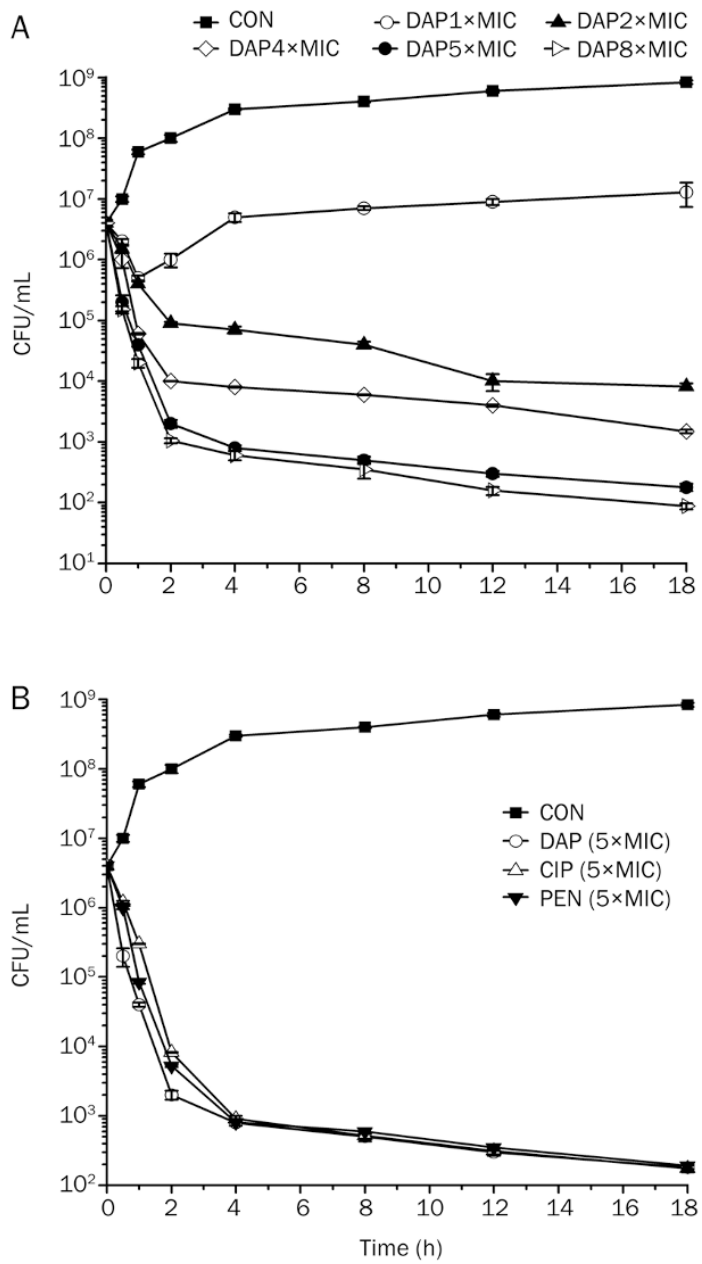

Figure 1. Daptomycin exhibits rapid bactericidal activity against Bacillus anthracis AP422. CON, DAP, PEN, CIP represent the control, daptomycin, penicillin G and ciprofloxacin, respectively. (A) Daptomycin (1× MIC to 8× $\mathrm{MIC}$ ) acted on AP422, and it displays rapid and concentration- dependent bactericidal activity against Bacillus anthracis AP422. (B) The effect of daptomycin against $B$ anthracis was equal to those of ciprofloxacin and penicillin $\mathrm{G}$. The data are representative of those from three independent experiments, and error bars indicate standard deviations.

quently, the number of CFUs decreased (Figure 2), suggesting that daptomycin could not kill dormant spores but prevented germinating spore from growing into vegetative $B$ anthracis. Similar results were shown when testing ciprofloxacin and penicillin $G$, which were both rapidly bactericidal against the $B$ anthracis spores as they germinated.

\section{Effects of daptomycin on the $B$ anthracis membrane potential}

We examined the effects of daptomycin on the membrane potential of $B$ anthracis using two independent methods. The fluorometric assay used $\mathrm{DiSC}_{3}(5)$, a membrane potentialsensitive fluorescent probe that inserts into the membrane and quenches its own fluorescence depending on the membrane potential. If drugs disrupt the membrane potential, the probe will be released into the medium, causing the fluorescence 


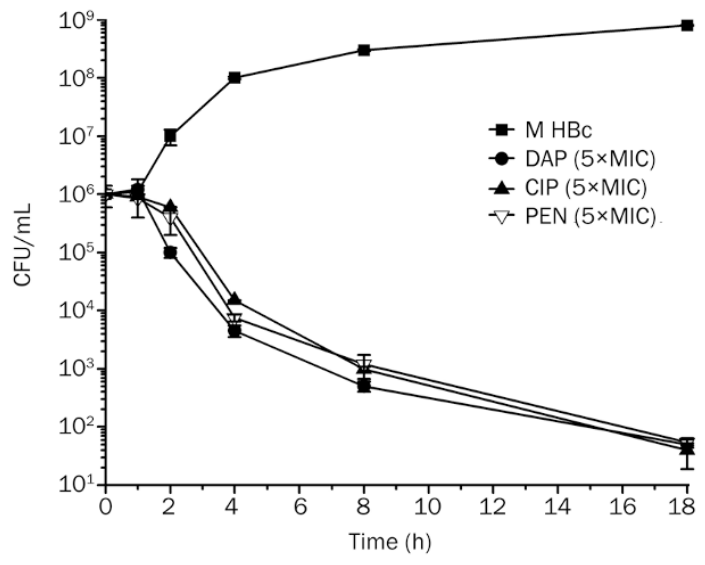

Figure 2. The effects of daptomycin on Bacillus anthracis spores. MHBc, DAP, PEN, and CIP represent the control, daptomycin, penicillin G, and ciprofloxacin, respectively. Daptomycin $(4 \mu \mathrm{g} / \mathrm{mL})$ did not kill dormant spores or reduce germination rates; however, the spores were apparently killed as they germinated. The effect of daptomycin is comparable to those of ciprofloxacin $(1 \mu \mathrm{g} / \mathrm{mL})$ and penicillin $\mathrm{G}(1 \mu \mathrm{g} / \mathrm{mL})$. The data are representative of those from three independent experiments.

to increase. Figure $3 \mathrm{~A}$ illustrates that $B$ anthracis vegetative cells that were exposed to $4 \mu \mathrm{g} / \mathrm{mL}$ daptomycin for $30 \mathrm{~min}$ showed a significant increase in fluorescence when compared with control cells, indicating membrane depolarization had occurred. The membrane potential was established in germinating spores after a 30-min incubation in MHBc. Daptomycin perturbed the membrane potential that was established in germinating spores, which was similar to the pore-forming peptide nisin and the proton ionophore CCCP. In contrast, ciprofloxacin and penicillin $\mathrm{G}$ did not cause significant changes in the membrane potential of vegetative cells or spores compared to the control level (Figure 3B).

The membrane potential was also confirmed by flow cytometry ratiometric measurement with $\mathrm{DiOC}_{2}(3)$. Consistent with the fluorometric analysis, daptomycin dissipated the $B$ anthracis AP422 membrane potential and caused concentrationdependent depolarization (Figure 4).

\section{Effects of daptomycin on bacterial membrane integrity}

We simultaneously monitored the membrane integrity by measuring the uptake of To-Pro-3 iodide, a membrane-impermeant dye. B anthracis AP422 were incubated in MHBc with 1,2 , and $4 \mu \mathrm{g} / \mathrm{mL}$ daptomycin for $60 \mathrm{~min}$, and no apparent increased fluorescence was observed, indicating that daptomycin did not disrupt the membrane integrity. When treated with CCCP and ciprofloxacin, the cells also displayed controllike values, which were in sharp contrast to those treated with nisin or penicillin $G$ and significantly increased the membrane permeability (Figure 5). The ultrastructure that was observed by TEM confirmed this finding and is shown in Figure 6. Control cells revealed envelopes with clearly discernible cell membranes, and the cell membrane appeared as an undulating barrier with few vesicular structures. No significant structural
A

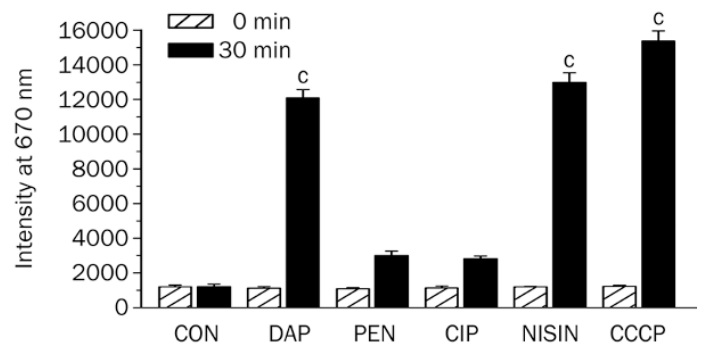

B

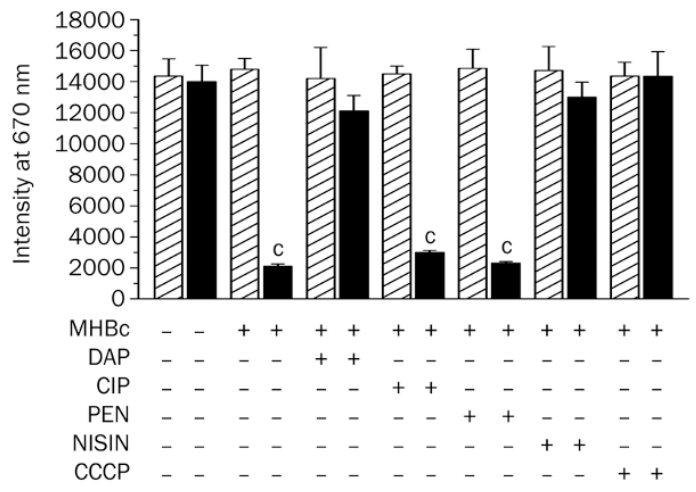

Figure 3. Daptomycin dissipates the membrane potential in $B$ anthracis, as measured by $\mathrm{DiSC}_{3}(5)$. CON, DAP, PEN, CIP, NISIN, and CCCP represent the control, daptomycin, penicillin G, ciprofloxacin, nisin, and CCCP, respectively. The fluorescence intensity is expressed as the mean signal of the 5-min trace. An increase in fluorescence indicates membrane depolarization. When exposed to daptomycin for $30 \mathrm{~min}$, the membrane potential is dissipated in vegetative $B$ anthracis $(A)$ and germinating spores (B). The data are representative of those from three independent experiments. ${ }^{\mathrm{c}} \mathrm{P}<0.01$.

damage occurred to the cytoplasmic membrane of $B$ anthracis AP422 cells that were treated with daptomycin, and cells treated with ciprofloxacin displayed unaffected cell membrane structures, in contrast to those treated with penicillin $G$ or nisin.

\section{Daptomycin elicits $\mathrm{K}^{+}$efflux from $B$ anthracis AP422 cells}

Potassium-ion-release experiments were performed using the potassium ion-sensitive, fluorescent probe PBFI. The addition of daptomycin to cells caused an immediate signal increase, indicating the release of intracellular potassium ions into the surrounding medium. These results were similar to those of cells treated with the potassium ionophore valinomycin (Figure 7). We also determined the intracellular sodium concentration using SBFI-AM, and the increased fluorescence ratio $340 / 380 \mathrm{~nm}$ indicated that the intracellular concentration of $\mathrm{Na}^{+}$increased. After the addition of daptomycin to cells, the fluorescence intensity ratio $340 / 380 \mathrm{~nm}$ increased, indicating an influx of sodium ions into the cells (Figure 8).

\section{Discussion}

Although the bactericidal activity of daptomycin against many clinically relevant Gram-positive bacteria including Bacillus 
A

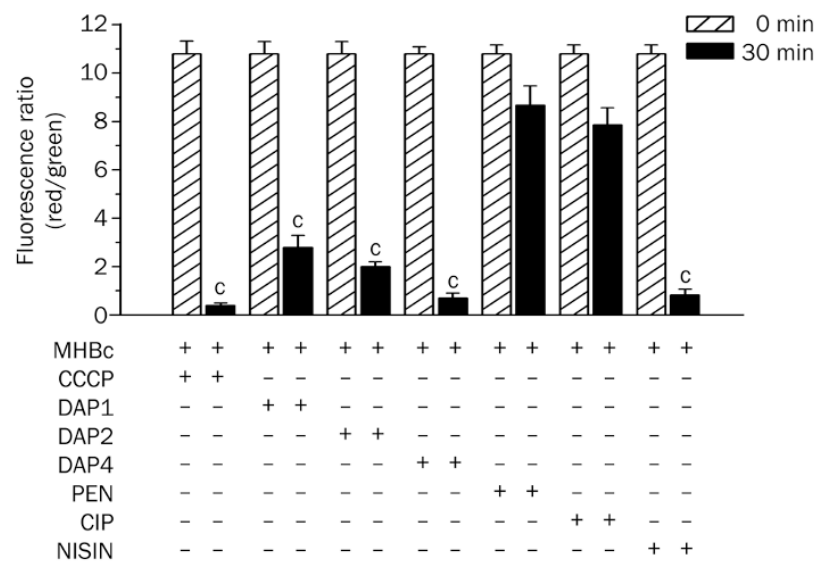

B

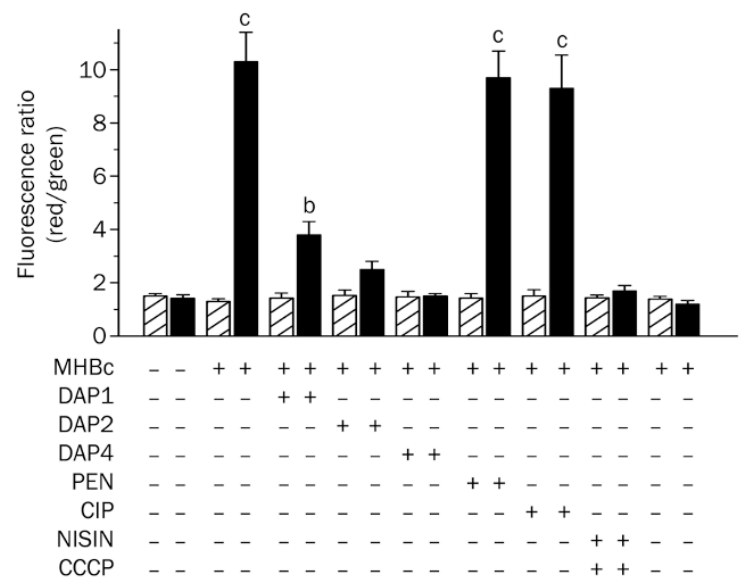

Figure 4. Daptomycin dissipates the membrane potential in $B$ anthracis, as measured by flow cytometry. CON, DAP, PEN, CIP, NISIN, and CCCP represent the control, daptomycin, penicillin G, ciprofloxacin, nisin, and CCCP, respectively. The fluorescence ratio (red/green) represents the membrane potential. When the fluorescence ratio decreased (30 min), the membrane potential is reduced. The results of antibiotics against vegetative $B$ anthracis $(A)$ and spores $(B)$ are consistent with those by $\mathrm{DiSC}_{3}(5)$, as above. The data are representative of those from three independent experiments. ${ }^{\mathrm{b}} P<0.05,{ }^{\mathrm{c}} P<0.01$.

species has been demonstrated ${ }^{[22,23]}$, limited data are available on $B$ anthracis. The effect of daptomycin on the sporulation and toxinogenicity of $B$ anthracis must be evaluated. Here, we investigated the in vitro activities of daptomycin against vegetative bacteria and spores. In our study, daptomycin exhibited good bactericidal activity against $B$ anthracis AP422 that was comparable to that of penicillin $G$ and ciprofloxacin with a MIC of $0.78 \mu \mathrm{g} / \mathrm{mL}$. As shown in Figure 1, daptomycin produced rapid and concentration-dependent bactericidal activity against $B$ anthracis AP422. The rapid killing of $B$ anthracis may prevent bacterial dissemination and diminish the host damage caused by released anthrax toxins, such as the protective antigen, lethal factor and edema factor. Identification of an antibiotic that kills $B$ anthracis at a high rate may improve treatment outcomes for this rapidly progressive, often fatal disease.

$B$ anthracis is complex because of its spore form. In this work, testing was also performed with spore preparations to determine whether daptomycin showed activity against spores. The delay in the rise in the spore population relative to vegetative $B$ anthracis was likely due to the time required for spores to germinate into vegetative bacteria because only vegetative bacteria can replicate. Our studies show that daptomycin could not kill dormant spores, which was consistent with those treated with penicillin $\mathrm{G}$ and ciprofloxacin. It has been described that spores cannot be killed by antibiotics because the spores have very compact structures such as the coat, which clearly plays a major role in spore resistance to antibiotics $^{[24-26]}$. It seems that the $B$ anthracis spore coat restricts the access of daptomycin to the inner regions of the spore, which prevents its binding and activity. However, the spores were killed immediately after they germinated; therefore, daptomycin prevented the outgrowth of germinating spores into vegetative $B$ anthracis.

In spite of its success on bactericidal activity, the mode of action of daptomycin is not fully understood ${ }^{[27,28]}$. One proposed mechanism of action is that daptomycin causes the dissipation of the bacterial membrane potential. Here, we reexamined the effects of daptomycin on the membrane potential of $B$ anthracis. Based upon our own observations, daptomycin dissipated the vegetative $B$ anthracis AP422 membrane potential and prevented the establishment of a membrane potential in germinating spores, and these effects were concentration-dependent. Daptomycin caused a rapid and severe efflux of intracellular potassium ions from $B$ anthracis cells. Our results of potassium efflux and sodium influx showed that ion channels or pores are not $\mathrm{K}^{+}$-specific; therefore, other ions could undergo efflux or influx. The probable reason for this phenomenon is that potassium-ion release deprived $B$ anthracis of the energy required for macromolecular synthesis, $\mathrm{Na}^{+}$$\mathrm{K}^{+}$ATPase or other proteins were inactivated, sodium influx or other ions effluxed, and then the cells died. However, the membrane permeabilization of the $B$ anthracis membrane did not occur, even when exposed to daptomycin at concentrations near $8 \times$ the MIC for $60 \mathrm{~min}$, which suggests that daptomycin acts without cell lysis or even significant damage to membrane integrity.

Notably, the mechanism of daptomycin on $B$ anthracis is fundamentally different from those of other tested antimicrobial agents. Ciprofloxacin, a DNA gyrase inhibitor, which is the recommended antibiotic treatment for $B$ anthracis infections, did not disrupt the membrane potential of vegetative cells or germinating spores and had no effect on membrane integrity. While penicillin $G$, which is also considered a treatment of choice for anthrax, did not cause membrane depolarization but increased membrane permeability to the nucleic acid dye Topro-3 in $B$ anthracis. The pore-forming peptide nisin reduced membrane potential with a loss of membrane integrity, while the proton ionophore CCCP reduced membrane potential to zero but did not cause membrane permeabilization. The rate of the membrane potential decrease that was caused by daptomycin was slower than that of nisin or CCCP.

Research has previously demonstrated that a variety of 
A
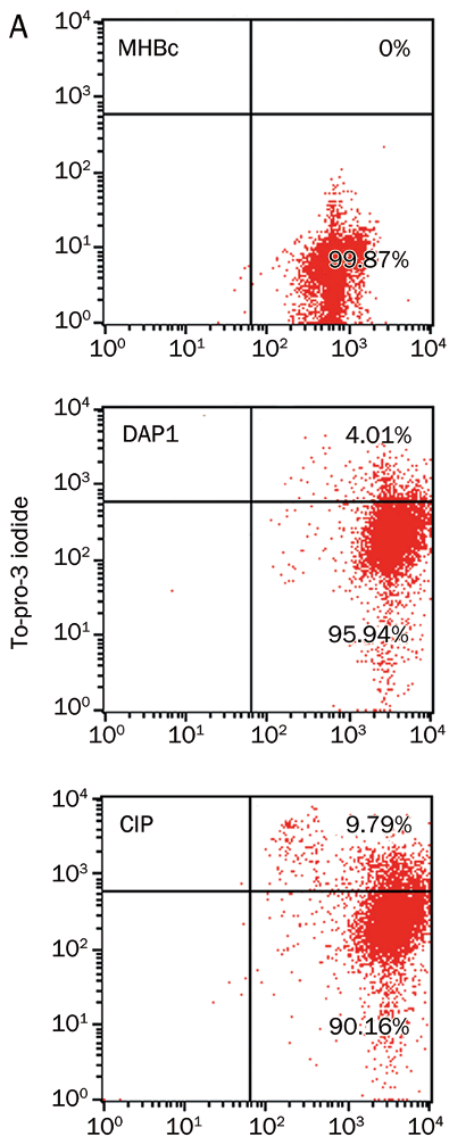
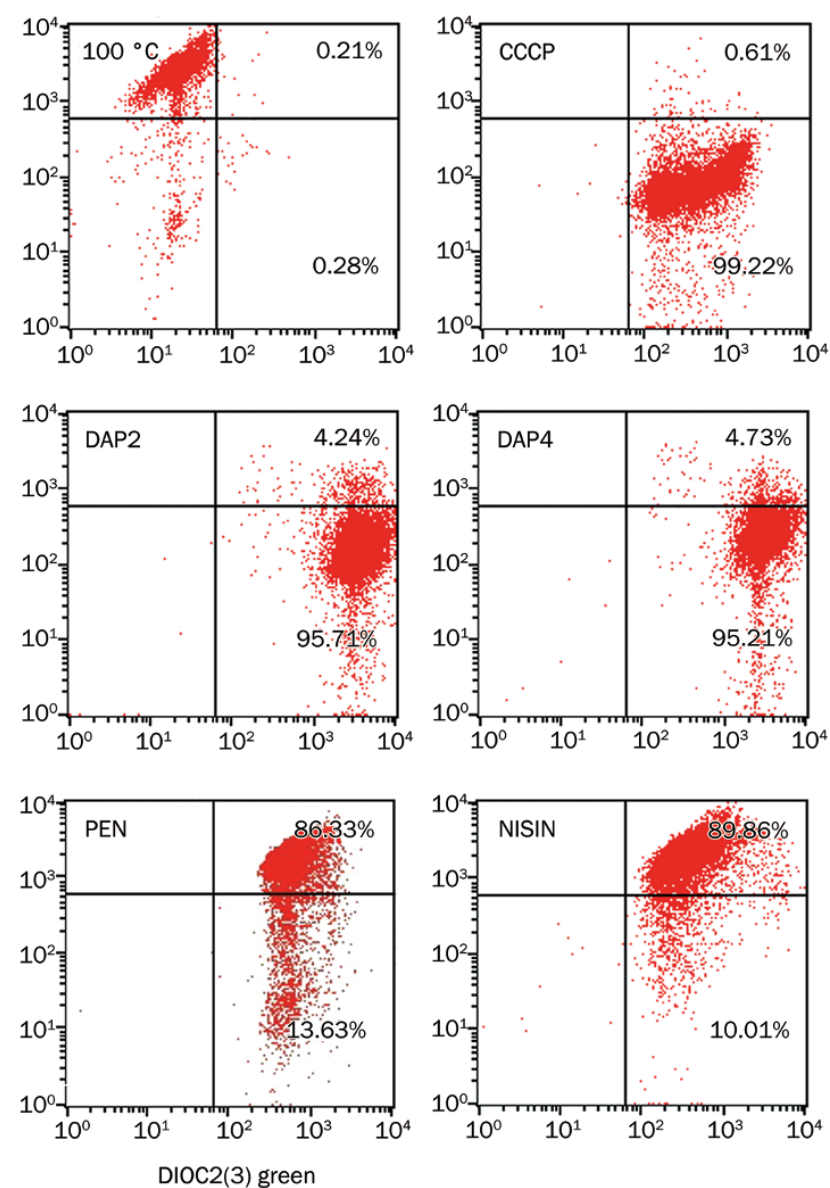

B

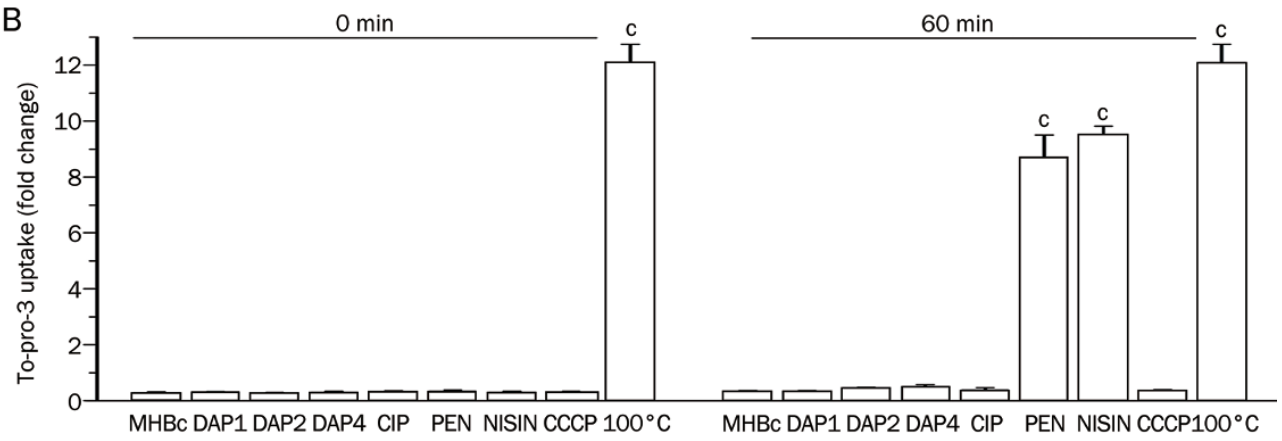

Figure 5. Effects of daptomycin on $B$ anthracis AP422 membrane integrity, as measured by flow cytometry. MHBc, DAP, PEN, and CIP represent

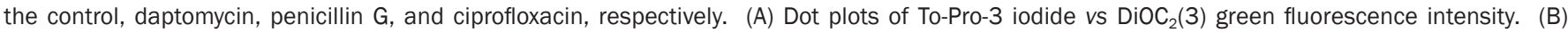
Correction of To-Pro-3 fluorescence, the ratio of the elevated far-red fluorescence of To-Pro-3 iodide/ $\mathrm{DiOC}_{2}(3)$ green fluorescence can be used as a sizeindependent measure of the membrane permeability. Cells treated with daptomycin for as long as 60 min showed no significant To-Pro-3 uptake. CCCP and ciprofloxacin displayed control-like values, which was in sharp contrast to those treated with nisin or penicillin $\mathrm{G}$. ${ }^{\mathrm{c}} P<0.01$.

antimicrobial peptides can reduce the membrane potential with a loss of membrane integrity ${ }^{[29]}$. However, daptomycin acts upon $B$ anthracis by reducing the membrane potential and not via disrupting membrane integrity. Potassium-ion release deprived $B$ anthracis of the energy required for macromolecular synthesis, such as synthesis of DNA, RNA and proteins (including toxin proteins) and finally resulted in bacterial death. The bactericidal activity of daptomycin against $B$ anthracis, which does not disrupt the membrane integrity, may have clinical advantages by reducing the release of proinflammatory bacterial components and exotoxins.

Collectively, daptomycin was demonstrated to kill vegetative $B$ anthracis and germinating spores by dissipating the membrane potential without disrupting the membrane integrity. The rapid bactericidal activity without lysis of $B$ anthracis indicates that daptomycin could serve as an attractive agent 

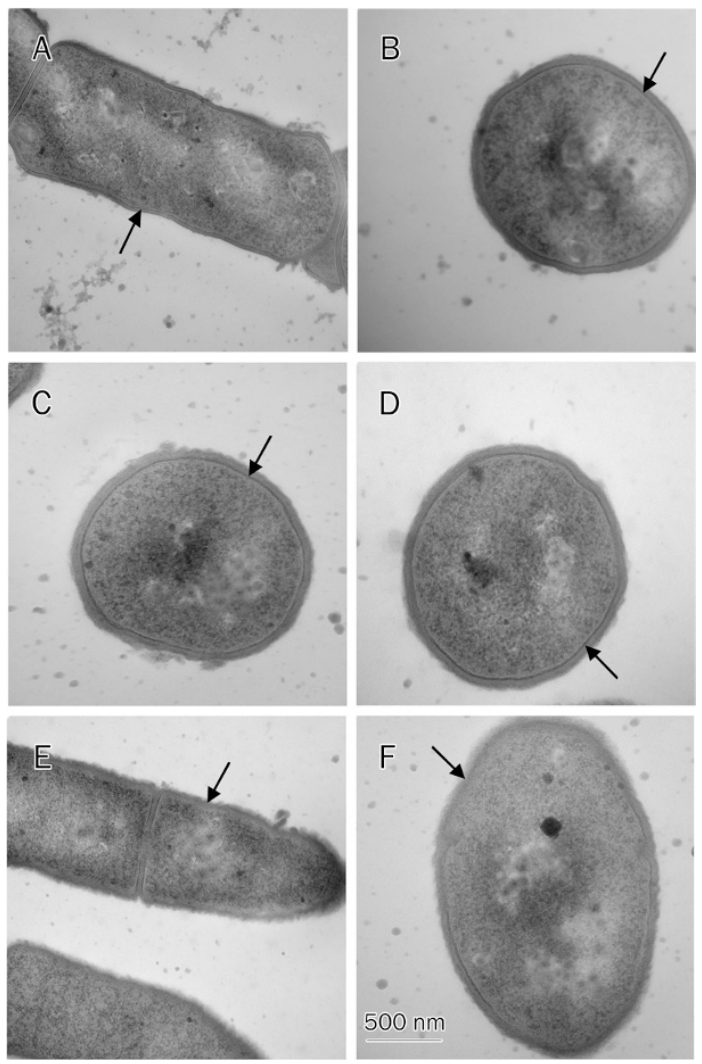

Figure 6. Transmission electron micrographs of $B$ anthracis AP422 cells treated with daptomycin and other antibiotics. (A) and (B) MHBc control; (C) $1 \mu \mathrm{g} / \mathrm{mL}$ daptomycin for $30 \mathrm{~min}$; (D) $4 \mu \mathrm{g} / \mathrm{mL}$ daptomycin for $30 \mathrm{~min}$; (E) $1 \mu \mathrm{g} / \mathrm{mL}$ penicillin $\mathrm{G}$ for $30 \mathrm{~min}$; and (F) $25 \mu \mathrm{g} / \mathrm{mL}$ nisin for $30 \mathrm{~min}$. No significant structural damage to the cytoplasmic membrane of $B$ anthracis AP422 cells that were treated with daptomycin was observed. Arrows point to the cell membrane; Scale bar, $500 \mathrm{~nm}$.

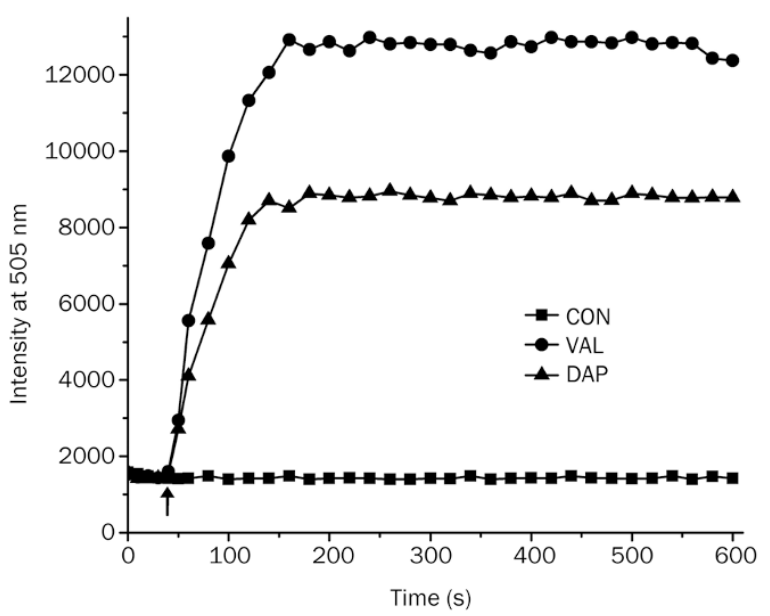

Figure 7. Daptomycin triggers potassium release from $B$ anthracis cells. PBFI was added to AP422 cells in a HEPES-glucose solution ( $0 \mathrm{~s}$ ); then, the cells were excited at $346 \mathrm{~nm}$, and the fluorescence emission was measured at $505 \mathrm{~nm}$ to establish a baseline signal. At approximately $45 \mathrm{~s}$ (arrow point), $4 \mu \mathrm{g} / \mathrm{mL}$ daptomycin or $10 \mu \mathrm{g} / \mathrm{mL}$ valinomycin were added.

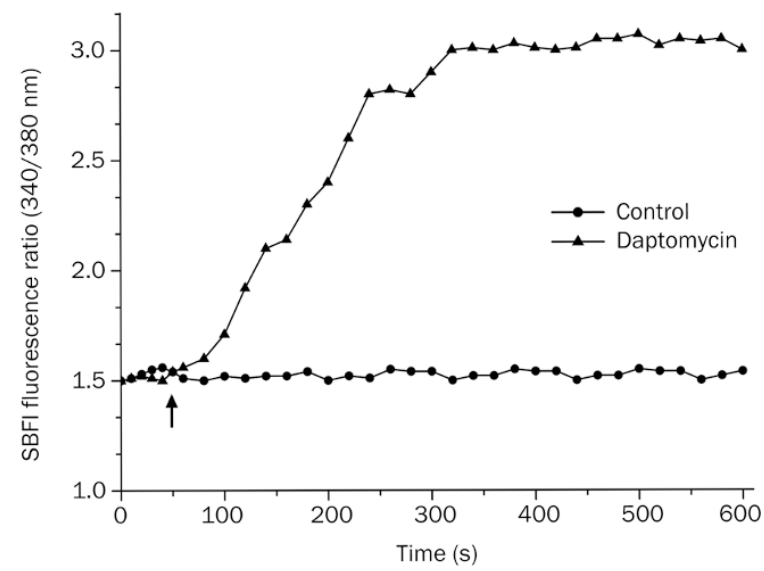

Figure 8. Influx assay of sodium ions into $B$ anthracis cells. SBFI-AM was added to AP422 cells in Locke's buffer $(0 \mathrm{~s})$; then, cells were excited at $340 / 380 \mathrm{~nm}$, and the fluorescence emission was measured at $505 \mathrm{~nm}$ to establish a baseline signal. At approximately $50 \mathrm{~s}$ (arrow point), $4 \mu \mathrm{g} / \mathrm{mL}$ daptomycin was added.

for prophylaxis or post-exposure treatment for $B$ anthracis infections. Further in vivo studies in non-human primate models of $B$ anthracis infection are now warranted.

\section{Acknowledgements}

This work was supported by the National High Technology Research and Development Program ("863" Program) of China (2012AA022001-03D). We thank Dr Chun-Jie LIU and Dr Yanchun WANG for the B anthracis AP422 strain and their assistance with experimental procedures. We thank Dr Xian-wen HU and Dr Yong-yi XI for helpful advice and reagents.

\section{Author contribution}

Hui-peng CHEN, Gang LIU, and Yu-hua XING designed the research; Yu-hua XING, Wei WANG, Su-qin DAI, Yu-xia LI, Yan LING, and Ti-yan LIU performed the research; Yu-hua XING, Jun-jie TAN, Guo-long QU, and Xue-qi FU analyzed the data; and Yu-hua XING wrote the paper.

\section{References}

1 Dixon TC, Meselson M, Guillemin J, Hanna PC. Anthrax. N Engl J Med 1999; 341: 815-26.

2 Jernigan JA, Stephens DS, Ashford DA, Omenaca C, Topiel MS, Galbraith $\mathrm{M}$, et al. Bioterrorism-related inhalational anthrax: the first 10 cases reported in the United States. Emerg Infect Dis 2001; 7: 933-44.

3 Inglesby TV, O'Toole T, Henderson DA, Bartlett JG, Ascher MS, Eitzen E, et al. Anthrax as a biological weapon, 2002: updated recommendations for management. JAMA 2002; 287: 2236-52.

4 Centers for Disease Control and Prevention (CDC). Investigation of bioterrorism-related anthrax and interim guidelines for exposure management and antimicrobial therapy. MMWR Morb Mortal Wkly Rep 2001; 50: 909-19.

5 Bradaric N, Punda-Polic V. Cutaneous anthrax due to penicillinresistant Bacillus anthracis transmitted by an insect bite. Lancet 1992; 340: 306-7. 
6 Coker PR, Smith KL, Hugh-Jones ME. Antimicrobial susceptibilities of diverse Bacillus anthracis isolates. Antimicrob Agents Chemother 2002; 46: 3843-5.

7 Chen Y, Tenover FC, Koehler TM. $\beta$-Lactamase gene expression in a penicillin-resistant Bacillus anthracis strain. Antimicrob Agents Chemother 2004; 48: 4873-7.

8 Brook I, Elliott TB, Pryor HI 2nd, Sautter TE, Gnade BT, Thakar JH, et al. In vitro resistance of Bacillus anthracis Sterne to doxycycline, macrolides and quinolones. Int J Antimicrob Agents 2001; 18: 55962.

9 Athamna A, Athamna M, Abu-Rashed N, Medlej B, Bast DJ, Rubinstein E. Selection of Bacillus anthracis isolates resistant to antibiotics. J Antimicrob Chemother 2004; 54: 424-8.

10 Price LB, Volger A, Pearson T, Busch JD, Schupp JM, Keim P. In vitro selection and characterization of Bacillus anthracis mutants with high-level resistance to ciprofloxacin. Antimicrob Agents Chemother 2003; 47: 2362-5.

11 Choe $\mathrm{CH}$, Bouhaouala SS, Brook I, Elliot TB, Knudson GB. In vitro development of resistance to ofloxacin and doxycycline in Bacillus anthracis Sterne. Antimicrob Agents Chemother 2000; 44: 1766.

12 Tally FP, Zeckel M, Wasilewski MM, Carini C, Berman CL, Drusano GL, et al. Daptomycin: a novel agent for gram-positive infections. Expert Opin Investig Drugs 1999; 8: 1223-38.

13 Silverman JA, Perlmutter NG, Shapiro HM. Correlation of daptomycin bactericidal activity and membrane depolarization in Staphylococcus aureus. Antimicrob Agents Chemother 2003; 47: 2538-44.

14 Heine HS, Bassett J, Miller L, Purcell BK, Byrne WR. Efficacy of Daptomycin against Bacillus anthracis in a murine model of anthrax spore inhalation. Antimicrob Agents Chemother 2010; 54: 4471-3.

15 Clinical and Laboratory Standards Institute. Methods for dilution antimicrobial susceptibility tests for bacteria that grow aerobically; approved standard-ninth edition. CLSI document M07-A9 2012. USA.

16 Heine HS, Bassett J, Miller L, Hartings JM, Ivins BE, Pitt ML, et al. Determination of antibiotic efficacy against Bacillus anthracis in a mouse aerosol challenge model. Antimicrob Agents Chemother 2007; 51: 1373-9.

17 Wu M, Hancock RE. Interaction of the cyclic antimicrobial cationic peptide bactenecin with the outer and cytoplasmic membrane. J Biol Chem 1999; 274: 29-35.

18 Novo D, Perlmutter NG, Hunt RH, Shapiro HM. Accurate flow cytometric membrane potential measurement in bacteria using diethyloxacarbocyanine and a ratiometric technique. Cytometry 1999; 35: 55-63.

19 Marrie TJ, Costerton JW. Scanning and transmission electron microscopy of in situ bacterial colonization of intravenous and intraarterial catheters. J Clin Microbiol 1984; 19: 687-93.

20 Herranz C, Cintas LM, Hernandez PE, Moll GN, Driessen AJ. Enterocin $P$ causes potassium ion efflux from Enterococcus faecium T136 cells. Antimicrob Agents Chemother 2001; 45: 901-4.

21 Kader MA, Lindberg S. Uptake of sodium in protoplasts of saltsensitive and salt-tolerant cultivars of rice, Oryza sativa L. determined by the fluorescent dye SBFI. J Exp Bot 2005; 56: 3149-58.

22 Braga PC, Ricci D, Dal Sasso M. Daptomycin morphostructural damage in Bacillus cereus visualized by atomic force microscopy. J Chemother 2002; 14: 336-41.

23 Diane MC, Maria DA. In vitro activities of daptomycin, ciprofloxacin, and other antimicrobial agents against the cells and spores of clinical isolates of Bacillus species. J Clin Microbiol 2006; 44: 3814-8.

24 Louie A, VanScoy BD, Brown DL, Kulawy RW, Heine HS, Drusano GL. Impact of spores on the comparative efficacies of five antibiotics for treatment of Bacillus anthracis in an in vitro hollow fiber pharmacodynamic model. Antimicrob Agents Chemother 2012; 56: 122939.

25 Setlow P. Resistance of bacterial spores. In: Storz G, Hengge RA, editors. In Bacterial Stress Responses. Washington, DC, USA: ASM Press 2000; p 217-30.

26 Nicholson WL, Munakata N, Horneck G, Melosh HJ, Setlow P. Resistance of Bacillus endospores to extreme terrestrial and extraterrestrial environments. Microbiol Mol Biol Rev 2000; 64: 548-72.

27 Suzana KS, Robert EW. Mode of action of the new antibiotic for Gram-positive pathogens daptomycin: Comparison with cationic antimicrobial peptides and lipopeptides. Biochim Biophys Acta 2006; 1758: 1215-23.

28 Laganas V, Alder J, Silverman JA. In vitro bactericidal activities of daptomycin against Staphylococcus aureus and Enterococcus faecalis are not mediated by inhibition of lipoteichoic acid biosynthesis. Antimicrob Agents Chemother 2003; 47: 2682-4.

29 Gut IM, Blanke SR, Donk WA. Mechanism of inhibition of Bacillus anthracis spore outgrowth by the lantibiotic nisin. ACS Chem Biol 2011; 6: 744-52. 